\title{
CXCL12/SDF-1 $\alpha$ induces migration via SRC-mediated CXCR4-EGFR cross-talk in gastric cancer cells
}

\author{
YU CHENG, JINGLEI QU, XIAOFANG CHE, LING XU, NA SONG, \\ YANJU MA, JING GONG, XIUJUAN QU and YUNPENG LIU
}

\begin{abstract}
Department of Medical Oncology, The First Hospital of China Medical University, Shenyang, Liaoning 110001, P.R. China
\end{abstract}
Received November 12, 2015; Accepted April 21, 2017

DOI: $10.3892 / 01.2017 .6389$

\begin{abstract}
Metastasis is the primary cause of mortality in patients with advanced gastric carcinoma, and multiple signaling pathways promote the development of this condition. Stromal cell-derived factor-1 (SDF-1 $\alpha /$ CXCL12), the main ligand for $\mathrm{CXC}$ chemokine receptor-4 (CXCR4), serves an important role in gastric cancer cell migration. Previous studies have demonstrated that CXCL12 could also stimulate the secretion of epidermal growth factor receptor (EGFR) ligands, including amphiregulin and heparin-binding epidermal growth factor-like growth factor, from gastric cancer cells, resulting in an increase in the ability of migration. However, it remains to be elucidated whether CXCL12 activates EGFR intracellular signaling and therefore stimulates migration in gastric cancer. The present study demonstrated that three gastric cancer cell lines, SGC-7901, MGC-803 and BGC-823, all expressed CXCR4. The increased chemotactic migratory ability stimulated by CXCL12 was effectively abrogated by the CXCR 4 antagonist, AMD3100. Furthermore, a rapid phosphorylation of Akt/extracellular signal-regulated kinase (ERK)/EGFR was demonstrated to be involved in CXCL12/CXCR4-induced gastric cancer cell migration. Knockdown of EGFR gene or the use of a monoclonal antibody against EGFR (C225) blocked the activation of ERK/Akt and partially prevented the ability of migration induced by CXCL12, which indicated that EGFR signaling is located downstream of CXCL12. In addition, it was also revealed that the activation of non-receptor tyrosine kinase c-steroid receptor co-activator (SRC) and the formation of the SRC/EGFR heterodimer are promoted by CXCL12, whereas the SRC inhibitor, PP2, blocks the
\end{abstract}

Correspondence to: Professor Xiujuan Qu or Professor Yunpeng Liu, Department of Medical Oncology, The First Hospital of China Medical University, 155 North Nanjing Street, Shenyang, Liaoning 110001, P.R. China

E-mail: qu_xiujuan@hotmail.com

E-mail: cmuliuyunpeng@hotmail.com

Key words: stromal cell-derived factor-1, non-receptor tyrosine kinase c-steroid receptor co-activator, epidermal growth factor receptor, gastric cancer
SRC/EGFR heterodimer and the activation of EGFR, as well as CXCR4-meditated migration induced by CXCL12. The present results indicated that SRC mediates a potential CXCR4-EGFR cross-talk, and thereby utilizes the EGFR-Akt/ERK axis to promote cellular migration. The present study provided a novel insight into the underlying regulatory mechanisms of the CXCL12/CXCR4 pathway in gastric cancer cell migration.

\section{Introduction}

Gastric cancer was the fourth most prevalent cancer and caused the second highest number of cancer-associated mortalities worldwide in 2012 (1). Metastasis is the main factor contributing to the poor prognosis of patients with gastric cancer (2). In cases of metastasis, patients lose the opportunity to receive a curative treatment, and the response rate of chemotherapy and targeted drugs is limited (3). Therefore, exploring the underlying molecular mechanisms that facilitate the development of gastric cancer may help to identify potential molecular targets and biomarkers for therapeutic intervention in patients with gastric cancer.

Stromal cell-derived factor-1 (SDF-1 $\alpha)$, also termed CXCL12, is a member of the CXC chemokine family, which binds to its receptor, CXC chemokine receptor-4 (CXCR4), performing an important role in inflammation, immune surveillance and tissue regeneration as well as oncogenesis $(4,5)$. The CXCL12/CXCR4 axis modulates a number of downstream signaling pathways associated with chemotaxis, tumor cell proliferation and metastasis (5). Previous clinical studies have revealed that the overexpression of CXCL12/CXCR4 is associated with poor prognosis and is involved in the lymph node and distant metastasis of gastric carcinoma $(6,7)$. However, CXCL12/CXCR4 axis-mediated signaling pathways in gastric cancer cells are yet to be fully elucidated. A number of previous studies have established that G-protein-coupled receptors (GPCRs), including CXCR4, are able to transactivate epidermal growth factor receptor (EGFR) via a disintegrin and metalloprotease (ADAM) domain $(8,9)$. This cross-activation is involved in prostate cancer cell proliferation through CXCL12/CXCR4-induced ectodomain shedding of EGFR ligands (10). Yasumoto et al (11) reported that CXCL12 and heparin-binding epidermal growth factor-like growth factor (HB-EGF) collaboratively stimulate the secretion of amphiregulin from gastric cancer cells 
and promote peritoneal metastasis. However, the underlying mechanism by which other cross-activation accounts for the regulation of CXCL12/CXCR4-induced EGFR activation in gastric cancer requires further investigation.

In cross-talk studies, GPCRs have also been established to transactive receptor pathways through ligand-independent mechanisms, involving a number of key mediators of growth factor signalling, including SHC, growth factor receptor bound 2 (GRB2) and SOS, in addition to mitogen-activated protein kinase activation $(12,13)$. Fischer et al (14) reported that the GPCR-mediated activation of c-MET occurs via NADPH-induced release of reactive oxygen species. In prostate cancer cells, lipid rafts were reported as the key site of CXCR4 transactivation of the human epidermal growth factor receptor 2 (HER2) receptor (15). SRC, a non-receptor tyrosine kinase, is expressed ubiquitously in human malignancies and is involved in numerous signaling pathways (16). SRC contributes to CXCL12/CXCR4-induced breast and prostate cancer bone metastasis $(15,17)$. SRC may also promote the phosphorylation of protein-tyrosine kinases, including EGFR, HER2 and c-MET, at the plasma membrane through its intracellular domain (18-20), as well as mediate tumor cell proliferation and resistance to HER2 or EGFR inhibitors $(10,21,22)$. Our previous study demonstrated that SRC combines with EGFR to regulate EGFR activation in gastric cancer cells and antagonizes apoptosis induced by tumor necrosis factor-related apoptosis-inducing ligand (23). However, it is unknown whether the CXCL12/CXCR4 axis-regulated transactivation of EGFR is mediated in an SRC-dependent manner.

The present study demonstrated that the formation of the SRC/EGFR heterodimer contributes to constitutive EGFR activation, and in turn, activated EGFR causes the activation of ERK/Akt signaling pathways and promotes gastric cancer cell migration.

\section{Materials and methods}

Cells and cell culture. Human gastric MGC-803, BGC-823, SGC-7901 cell lines were obtained from the Type Culture Collection of the Chinese Academy of Sciences (Shanghai, China). Cells were cultured in RPMI-1640 medium (Gibco; Thermo Fisher Scientific, Inc., Waltham, MA, USA) containing with $10 \%$ fetal bovine serum (FBS; Gibco; Thermo Fisher Scientific, Inc.) and $1 \%$ penicillin-streptomycin in a humidified atmosphere of $95 \%$ air and $5 \% \mathrm{CO}_{2}$ at $37^{\circ} \mathrm{C}$.

Reagents and antibodies. Recombinant SDF-1 $\alpha$ was purchased from PeproTech (Rocky Hill, NJ, USA). The CXCR4 antagonist AMD3100 (cat. no. A5602), the phosphoinositide 3-kinase (PI3K)/Akt inhibitor LY294002 (cat. no. L9908) and the SRC inhibitor PP2 (cat. no. P0042) were obtained from Sigma-Aldrich (Merck KGaA, Darmstadt, Germany). The ERK inhibitor PD98059 (cat. no. V1191) was obtained from Promega Corporation (Madison, WI, USA). Dimethyl sulfoxide was used to dilute CXCR4 and PP2. Mouse anti-SRC (cat. no. SC-24621; dilution, 1:500) and rabbit anti- $\beta$-actin (cat. no. SC-1616; dilution, 1:1,000) antibodies were obtained from Santa Cruz Biotechnology, Inc. (Dallas, TX, USA). Anti-phosphorylated (p)-EGFR (Tyr1068; cat. no. 2234; 1:250), anti-EGFR (cat. no. 2646; 1:1,000), rabbit anti-Akt (cat. no. 9272; 1:1,000), anti-p-Akt (Ser473; cat. no.9271; 1:500), anti-ERK1/2 (cat. no.9102; 1:2,000), anti-p-ERK1/2 (Thr202/Tyr204; cat. no.7263; 1:500) and anti-p-SRC (Y416; cat. no.6943T; 1:500) antibodies were purchased from Cell Signaling Technology, Inc. (Danvers, MA, USA). Rabbit anti-CXCR4 antibodies were obtained from Abcam (Cambridge, UK).

Small interfering RNA (siRNA) transfection. The MGC-803 cells were seeded at a density of $2 \times 10^{5}$ cells/well on 6 -well plates and incubated overnight at $37^{\circ} \mathrm{C}$. The cells were transfected with siRNAs using Lipofectamine ${ }^{\circledR} 2000$ (Invitrogen; Thermo Fisher Scientific, Inc.) according to the manufacturer's protocol. The siRNA sequence (Genepharm, Inc., Sunnyvale, CA, USA) for EGFR was as follows: 5'-GCCUUUGAGAAC CUAGAAATT-3', and the control sequence was: 5'-AATTCT CCGAACGTGTCACGT-3'. After $72 \mathrm{~h}$ of transient transfection at $37^{\circ} \mathrm{C}$, the cells were analyzed using western blotting to examine the effect of EGFR siRNA.

Western blot analysis. Cells were seeded at a density of $2 \times 10^{5}$ cells/well on 6-well plates and incubated overnight at $37^{\circ} \mathrm{C}$. Cells were treated with CXCL12 (100 ng/ml) for $5 \mathrm{~min}, 30 \mathrm{~min}$ or $3 \mathrm{~h}$. Cells were lysed in lysis buffer (1\% Triton X-100, $50 \mathrm{mM}$ Tris- $\mathrm{HCl} \mathrm{pH}$ 7.4, $150 \mathrm{mM} \mathrm{NaCl}, 10 \mathrm{mM}$ EDTA, $100 \mathrm{mM} \mathrm{NaF}$, $1 \mathrm{mM} \mathrm{Na} \mathrm{VO}_{4}, 1 \mathrm{mM}$ PMSF and $2 \mu \mathrm{g} / \mathrm{ml}$ aprotinin) on ice. The method of western blot analysis was described in our previous study (23).

Chemotaxis assay. Transwell migration assays were performed in 24-well chemotaxis chambers $(8-\mu \mathrm{m}$ pore size; Corning Incorporated, Corning, NY, USA). The pretreated cells (2x10 4 cells/well) with C225 $(10 \mu \mathrm{g} / \mathrm{ml})$, LY294002 $(50 \mu \mathrm{M})$ and PD98059 $(25 \mu \mathrm{M})$ were loaded onto the upper chamber with $200 \mu 1$ serum-free RPMI-1640 medium. The lower chambers contained $500 \mu \mathrm{l}$ of RPMI-1640 with $2.5 \% \mathrm{FBS}$, with or without $100 \mathrm{ng} / \mathrm{ml}$ of CXCL12. The cells in the chambers were incubated for $24 \mathrm{~h}$ at $37^{\circ} \mathrm{C}$. Non-migrated cells were removed from the upper surface of the chamber with a wet cotton swab and cells on the lower surface of the chamber were stained using the Giemsa-Wright method, as described previously (24). A total of 5 random fields per well were captured and counted in brightfield microscopy (magnification, x200; DMI3000 B; Leica Microsystems, Wetzlar, Germany).

Co-immunoprecipitation. Mouse anti-SRC, as previously described (1:200), or control IgG mixed with protein $\mathrm{G}$ agarose beads (GE Healthcare Bio-Sciences, Pittsburgh, PA, USA) and $200 \mu \mathrm{g}$ of MGC-803 cell lysate were incubated for $6 \mathrm{~h}$ at $4^{\circ} \mathrm{C}$. Immunoprecipitates were washed 4 times with lysis buffer as described previously. The method of immunoprecipitation was detailed in our previous study (23).

In situ proximity ligation assay (PLA). A PLA was performed to detect the SRC-EGFR heterodimer. MGC-803 cells were seeded at a density of $1 \times 10^{5}$ cells/well on 6 -well plates and incubated overnight at $37^{\circ} \mathrm{C}$. The cells were treated with CXCL12 and incubated for a further $3 \mathrm{~h}$ at $37^{\circ} \mathrm{C}$. Duolink in situ PLA (Olink AB, Uppsala, Sweden) was used according to the manufacturer's protocol. The mouse anti-SRC antibody 

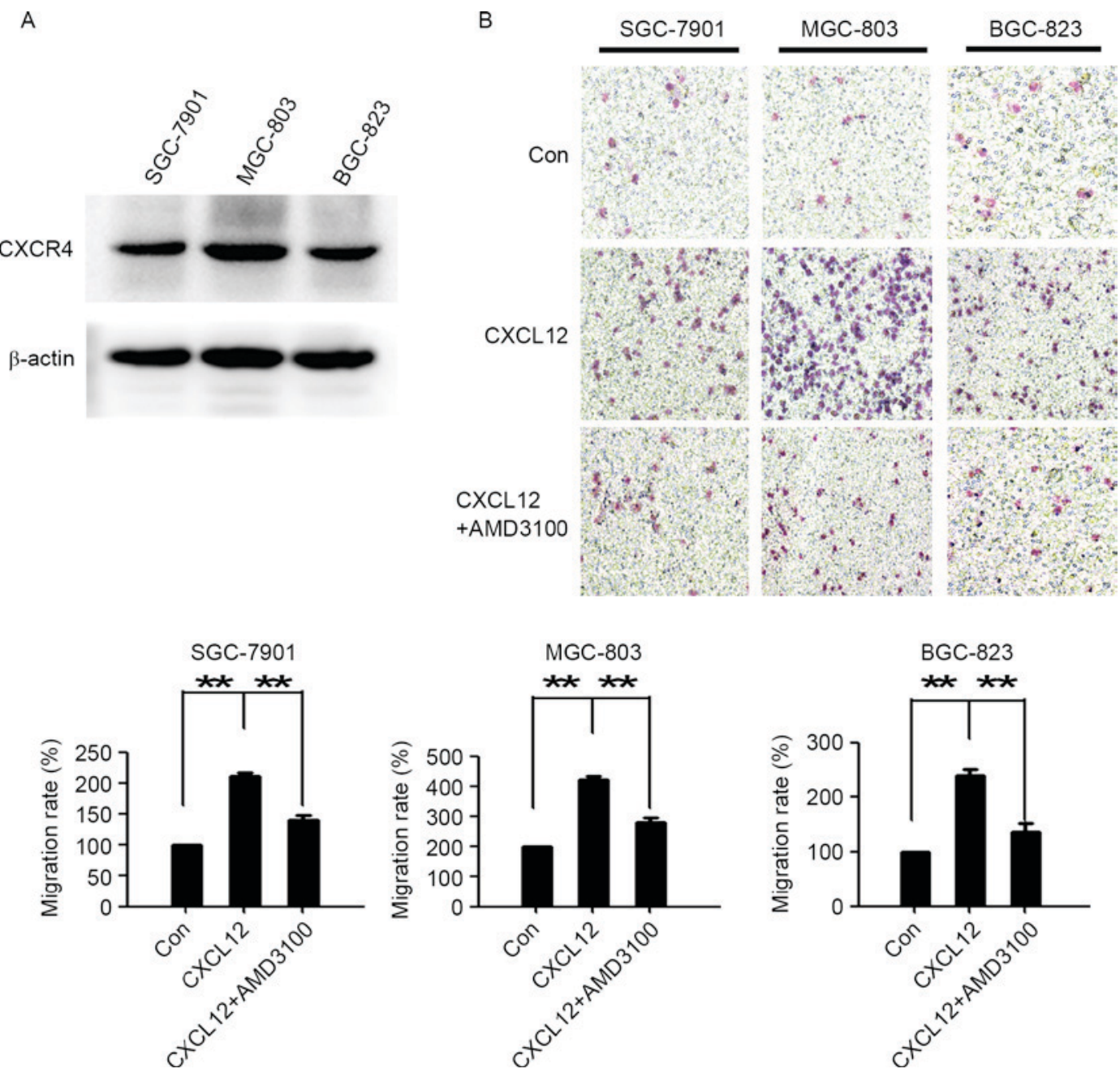

Figure 1. CXCL12/CXCR4 induces gastric cancer cell migration. (A) Western blot analysis demonstrated that the gastric cancer SGC-7901, MGC-803 and BGC-823 cell lines expressed CXCR4. (B) The SGC-7901, MGC-803 and BGC-823 cells were treated with CXCL12 (100 ng/ml) with or without AMD3100 $(10 \mu \mathrm{g} / \mathrm{ml})$, and cell migration was assessed using a Transwell assay (magnification, x200). Cells are stained using the Giemsa-Wright method (24). Data are presented as the mean \pm standard deviation of 3 independent experiments. ${ }^{* *} \mathrm{P}<0.01$. CXCL12, stromal cell-derived factor $1 \alpha$, SDF-1 $\alpha$; CXCR4, CXC chemokine receptor-4; AMD3100, CXCR4 antagonist; Con, control.

and rabbit anti-EGFR antibody, as previously described, were used as primary antibodies, at a dilution of 1:100. ProLong Gold Antifade reagent with DAPI (Molecular Probes; Thermo Fisher Scientific, Inc.) was used as the mounting medium. The method of PLA was otherwise as discussed in our previous study (23).

Statistical analysis. All the experimental data are expressed as the mean \pm standard deviation, and the mean values were calculated from $>3$ independent experiments. SPSS software (version 18; SPSS, Inc., Chicago, IL, USA) was used for statistical analysis. Statistical comparisons were made with Student's two-tailed t-tests. $\mathrm{P}<0.05$ was considered to indicate a statistically significant difference.

\section{Results}

CXCL12/CXCR4 induces gastric cancer cell migration. To investigate the role of the CXCL12/CXCR4 axis in gastric cancer cells, western blotting was used to examine the expression of CXCR4 in 3 gastric cancer cell lines (SGC-7901, MGC-803 and BGC-823). As presented in Fig. 1A, all 3 gastric cancer cell lines expressed CXCR4.
Compared with the untreated cells, CXCL12 evidently induced gastric cancer cell migration. AMD3100, a highly specific chemokine receptor CXCR4 antagonist (25), significantly reduced CXCL12-induced cell migration (Fig. 1B). These data demonstrated that the CXCL12/CXCR4 axis performs an important role in the migration of gastric cancer cells.

EGFR, ERK and Akt are involved in CXCL12-induced gastric cancer cell migration. To examine which pathways are involved in CXCL12-induced gastric cancer cell migration, cells were treated with CXCL12. Following treatment with $100 \mathrm{ng} / \mathrm{ml} \mathrm{CXCL12}$ for $5 \mathrm{~min}$, the levels of p-EGFR/Akt/ERK were upregulated (Fig. 2A). The migration ability induced by CXCL12 was partially suppressed with PD98059 $(25 \mu \mathrm{M})$, LY294002 $(50 \mu \mathrm{M})$ and anti-EGFR monoclonal antibody C225 (10 $\mu \mathrm{g} / \mathrm{ml}$; Fig. 2B). These data indicated that CXCL12 induces gastric cancer cell migration due to the activation of EGFR/Akt/ERK signaling pathways.

EGFR regulates the activation of ERK/Akt pathways in CXCL12-induced gastric cancer cell migration. To understand 
A

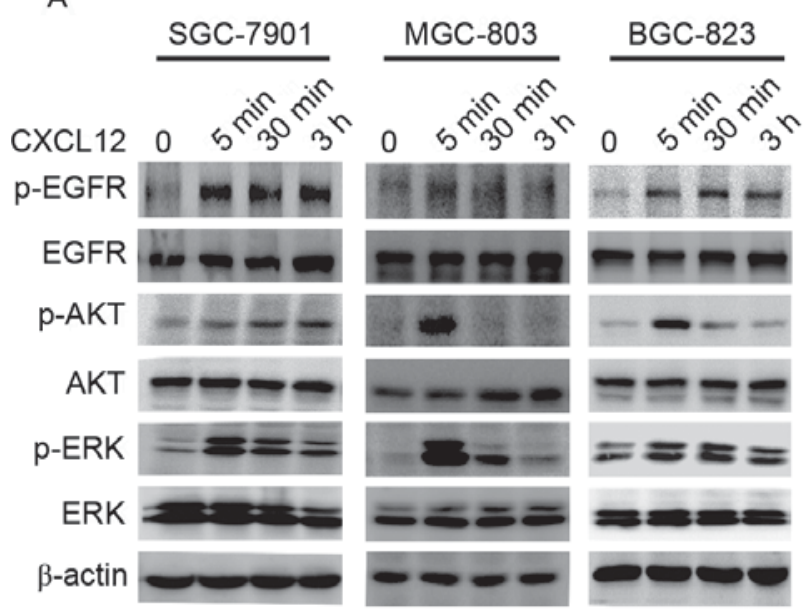

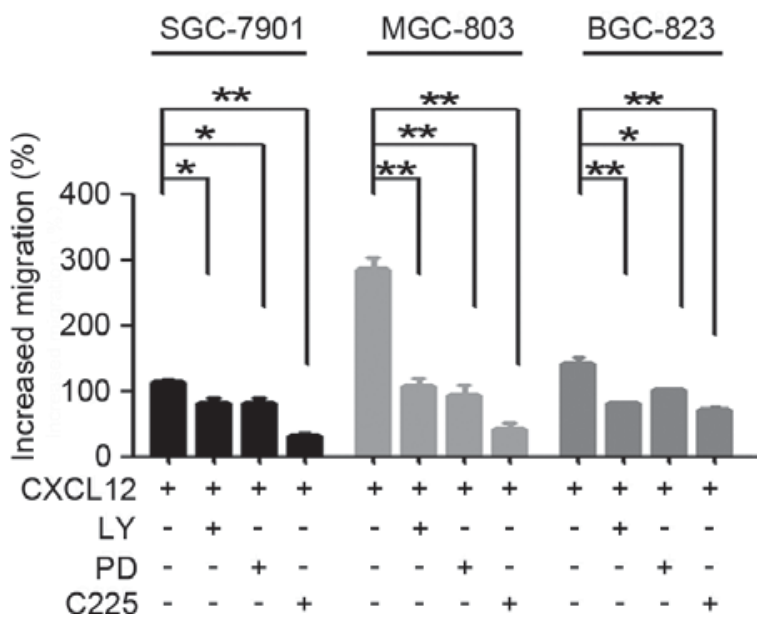

Figure 2. EGFR, ERK and Akt are involved in CXCL12-induced gastric cancer cell migration. (A) Serum-starved SGC-7901, MGC-803 and BGC-823 cells were treated with CXCL12 $(100 \mathrm{ng} / \mathrm{ml})$ for $5 \mathrm{~min}, 30 \mathrm{~min}$ or $3 \mathrm{~h}$, and the total protein levels of EGFR/Akt/ERK and p-EGFR/p-Akt/p-ERK were detected using western blot analysis. (B) The SGC-7901, MGC-803 and BGC-823 cells were treated with CXCL12 (100 ng/ml) with or without C225 (10 $\mu \mathrm{g} / \mathrm{ml}), \mathrm{LY} 294002$ $(50 \mu \mathrm{M})$ and PD98059 $(25 \mu \mathrm{M})$, and cell migration was assessed using a Transwell assay. Data are presented as the mean \pm standard deviation of 3 independent experiment. "P $<0.05,{ }^{* *} \mathrm{P}<0.01$. CXCL12, stromal cell-derived factor $1 \alpha$, SDF-1 $\alpha$; EGFR, epidermal growth factor receptor; p-EGFR, phosphorylated-EGFR; C225, cetuximab; LY, LY294002; PD, PD98059; ERK, extracellular signal-regulated kinase; p-ERK, phosphorylated-ERK.
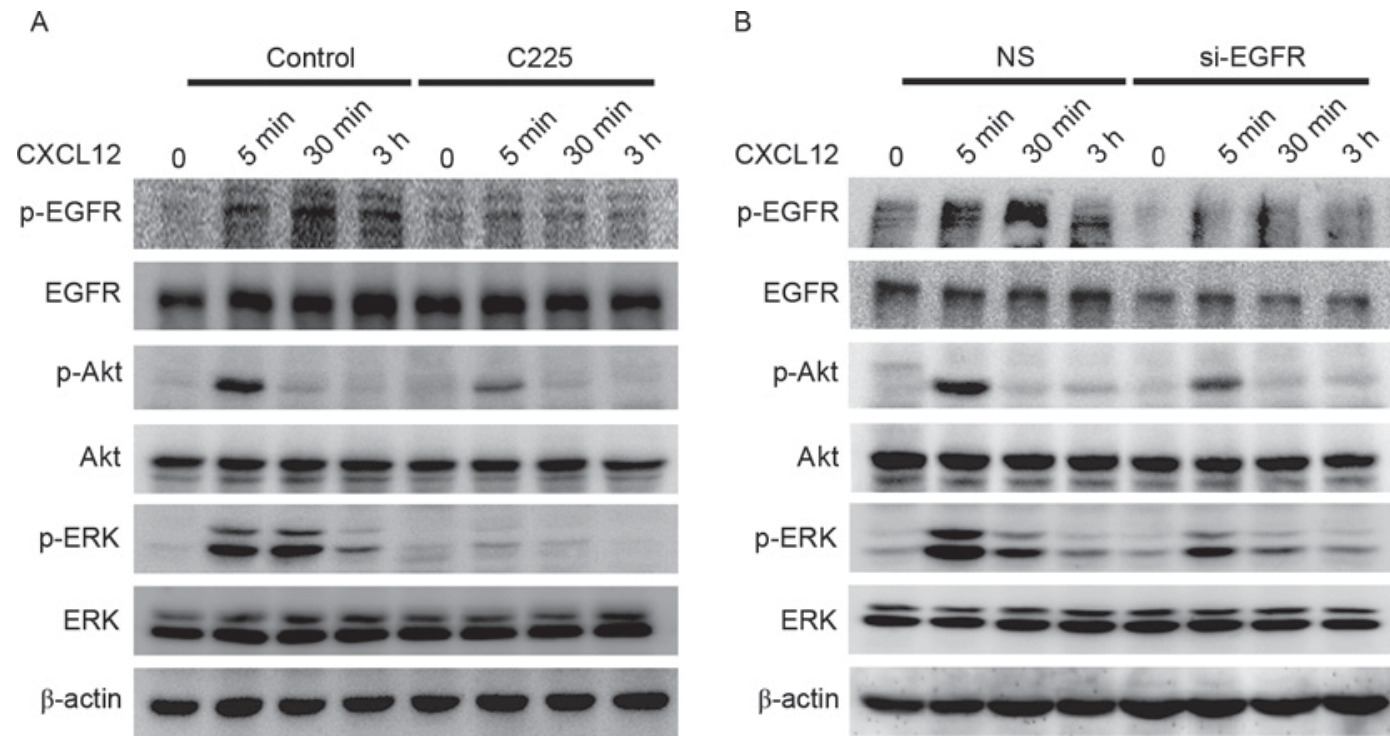

Figure 3. EGFR-regulated activation of the ERK/Akt signaling pathway in CXCL12-induced gastric cancer cell migration. (A) Serum-starved MGC-803 cells were pretreated with or without C225 $(10 \mu \mathrm{g} / \mathrm{ml})$ for $2 \mathrm{~h}$, cells were treated with CXCL12 $(100 \mathrm{ng} / \mathrm{ml})$ for $5 \mathrm{~min}, 30 \mathrm{~min}$ or $5 \mathrm{~h}$, and the total levels of EGFR/Akt/ERK and p-EGFR/p-Akt/p-ERK proteins were detected using western blot analysis. (B) Transient knockdown of the EGFR gene using EGFR siRNA for $72 \mathrm{~h}$, followed by $100 \mathrm{ng} / \mathrm{ml}$ CXCL12 for $5 \mathrm{~min}, 30 \mathrm{~min}$ or $3 \mathrm{~h}$. Western blot analysis was used to detect the total EGFR/Akt/ERK and p-EGFR/ p-Akt/p-ERK protein levels. CXCL12, stromal cell-derived factor $1 \alpha$, SDF-1 $\alpha$; C225, cetuximab; siRNA, small interfering RNA; NS, non-silenced; EGFR, epidermal growth factor receptor; p-EGFR, phosphorylated-EGFR; ERK, extracellular signal-regulated kinase; p-ERK, phosphorylated-ERK.

the role of EGFR in CXCL12-induced gastric cancer cell migration, it was investigated whether the activation of ERK/Akt is dependent on EGFR. The MGC-803 cells were pretreated with anti-EGFR monoclonal C225 antibody $(10 \mu \mathrm{g} / \mathrm{ml})$ for $2 \mathrm{~h}$ (Fig. 3A) or knockdown of the EGFR gene (Fig. 3B) was performed prior to stimulation with CXCL12 $(100 \mathrm{ng} / \mathrm{ml})$. A marked inhibition of CXCL12-induced activation of ERK and Akt signaling was observed at the $30 \mathrm{~min}$ and $3 \mathrm{~h}$ time points following EGFR inhibitor or si-EGFR treatment. These results demonstrated that CXCL12-induced gastric cancer cell migration is EGFR-Akt/ERK-dependent in MGC-803 cells.
CXCL12/CXCR4 effects the activation of EGFR and ERK/Akt via $S R C$. To assess which molecules modulate the activation of EGFR and the ERK/Akt signaling pathway, the effects of SRC on CXCL12-induced migration activity in MGC-803 cells was investigated. Rapid phosphorylation of SRC in MGC-803 cells was observed following stimulation with CXCL12 $(100 \mathrm{ng} / \mathrm{ml}$; Fig. 4A). The CXCL12-induced migration was inhibited by the SRC family kinase inhibitor PP2 (10 $\mu \mathrm{M}$; Fig. 4B), as was the activation of EGFR, ERK and Akt pathways (Fig. 4C). To determine whether CXCR4 contributes to the phosphorylation of SRC and EGFR, MGC-803 cells were pretreated with 
A

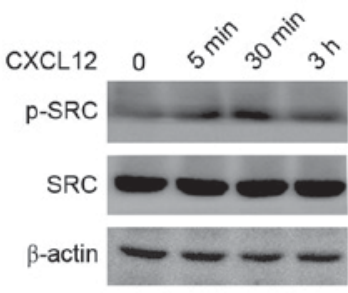

C

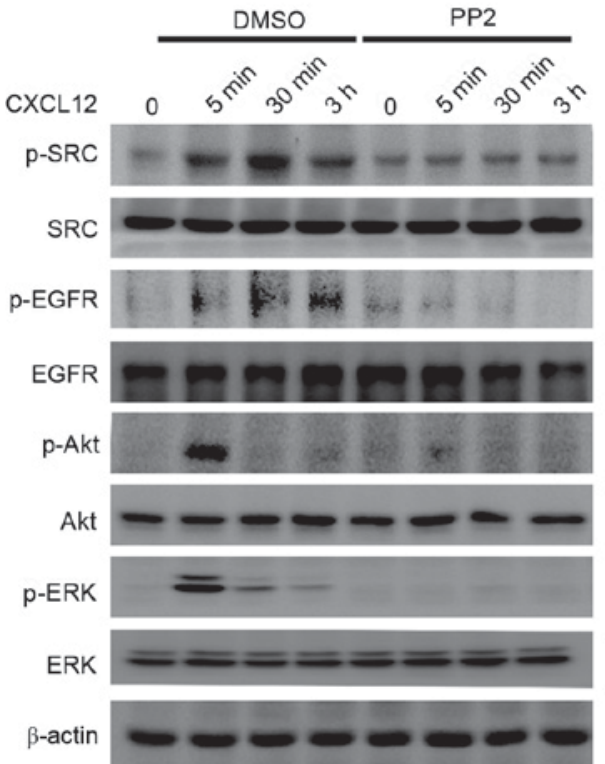

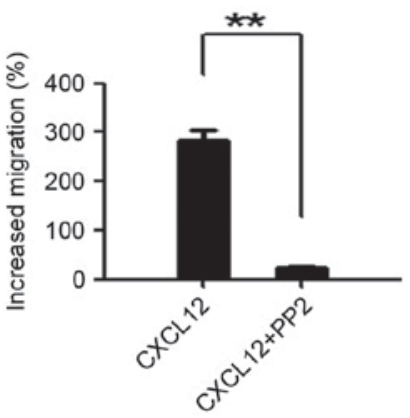

D

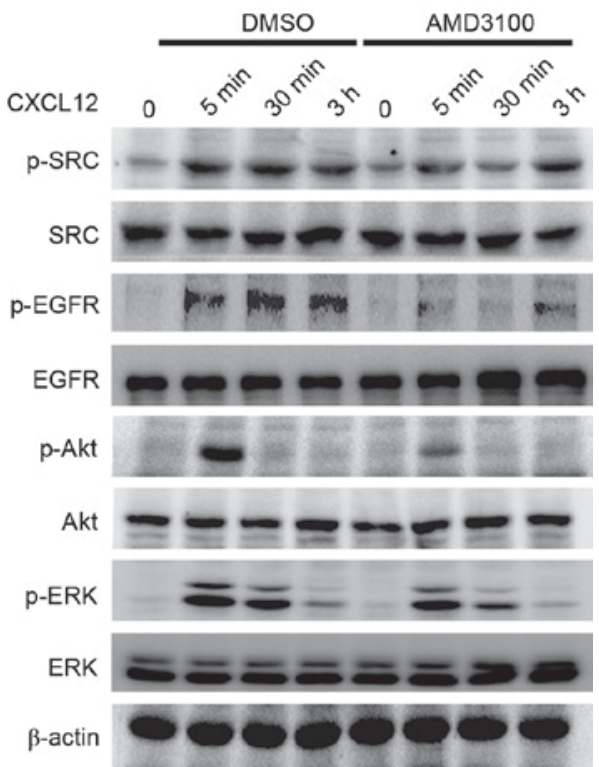

Figure 4. CXCL12 effects the activation of EGFR and ERK/Akt via SRC. (A) Serum-starved MGC-803 cells were treated with CXCL12 (100 ng/ml) for $5 \mathrm{~min}, 30 \mathrm{~min}$ or $3 \mathrm{~h}$, and p-SRC was analyzed using western blot analysis. (B) The MGC-803 cells were treated with CXCL12 (100 ng/ml) with or without PP2 $(10 \mu \mathrm{M})$, and cell migration was assessed using a Transwell assay. Data are presented as the mean \pm standard deviation of 3 independent experiment. ${ }^{* *} \mathrm{P}<0.01$. (C) Serum-starved MGC-803 cells were pretreated with or without PP2 for $2 \mathrm{~h}$, then cells were treated with CXCL12 (100 ng/ml) for the indicated times and western blot analysis was used to examine the total levels of EGFR/Akt/ERK and p-EGFR/p-Akt/p-ERK protein. (D) Serum-starved MGC-803 cells were pretreated with or without AMD3100 for $2 \mathrm{~h}$, cells were incubated with CXCL12 (100 ng/ml) for $5 \mathrm{~min}, 30 \mathrm{~min}$ or $3 \mathrm{~h}$, and the total EGFR/Akt/ERK and p-EGFR/p-Akt/p-ERK protein levels were examined using western blot analysis. CXCL12, stromal cell-derived factor 1 $\alpha$, SDF-1 $\alpha$; PP2, SRC inhibitor; EGFR, epidermal growth factor receptor; p-EGFR, phosphorylated-EGFR; ERK, extracellular signal-regulated kinase; p-ERK, phosphorylated-ERK; DMSO, dimethyl sulfoxide.

AMD3100 (10 $\mu \mathrm{g} / \mathrm{ml})$, a highly specific chemokine receptor CXCR4 antagonist (25), $2 \mathrm{~h}$ prior to stimulation with CXCL12. The results demonstrated that the inhibition of CXCR4 reduced the activation of SRC, EGFR and the downstream ERK/Akt signaling induced by CXCL12 (Fig. 4D).

Formation of the SRC/EGFR heterodimer is induced by CXCL12. To elucidate the interaction between SRC and EGFR, a co-immunoprecipitation assay was performed following CXCL12 treatment. Co-immunoprecipitation experiments demonstrated that the interaction between EGFR and SRC was enhanced by CXCL12 (Fig. 5A). The formation of SRC/EGFR heterodimers by Duolink in situ PLA was also evaluated. This method confirmed the promotion of the interaction between SRC and EGFR by CXCL12, with red fluorescent signals indicating the presence of the SRC-EGFR heterodimer (Fig. 5B). Compared with CXCL12 alone, PP2 reversed the complex of SRC/EGFR promoted by CXCL12 (Fig. 5C). These results indicated that CXCL12/CXCR4 induced gastric cancer migration via the formation of SRC/EGFR heterodimers.

\section{Discussion}

CXCL12/CXCR4 signaling was initially established as a regulator of B lymphocyte chemoattractant (26). Later, it was reported that CXCR4 performs an important role in tumor cell survival, proliferation, migration and stemness (27). The binding of CXCL12 to CXCR4 leads to activation of numerous downstream signaling pathways, including MAPK-ERK, PI3K-Akt-NF- $\kappa \mathrm{B}$ and c-Jun N-terminal kinase, and also modulates tumor progression (5). In the present study, it was observed that 3 gastric cancer cell lines express different levels of CXCR4. Using AMD3100, a highly specific chemokine receptor CXCR4 antagonist (25), the activation of ERK/Akt signaling and the migration ability promoted by CXCL12 were reduced. This supports the central role of the CXCL12/CXCR4 axis in gastric cancer cell migration. 
A

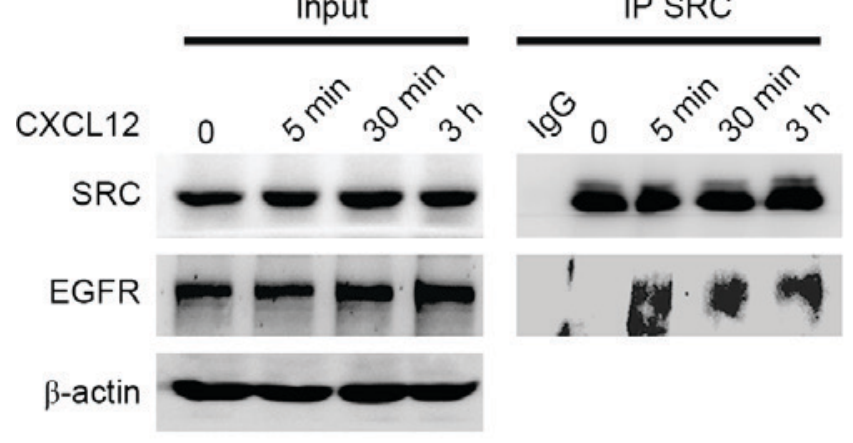

C

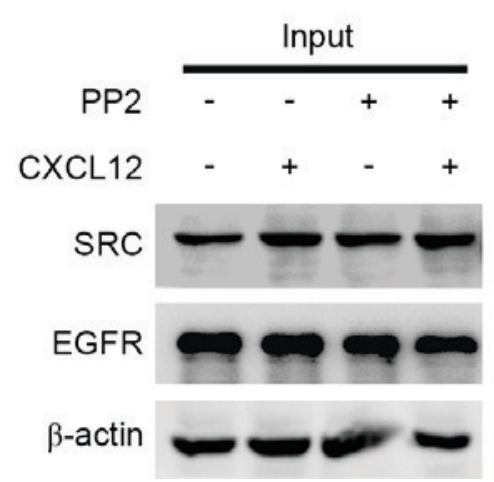

B

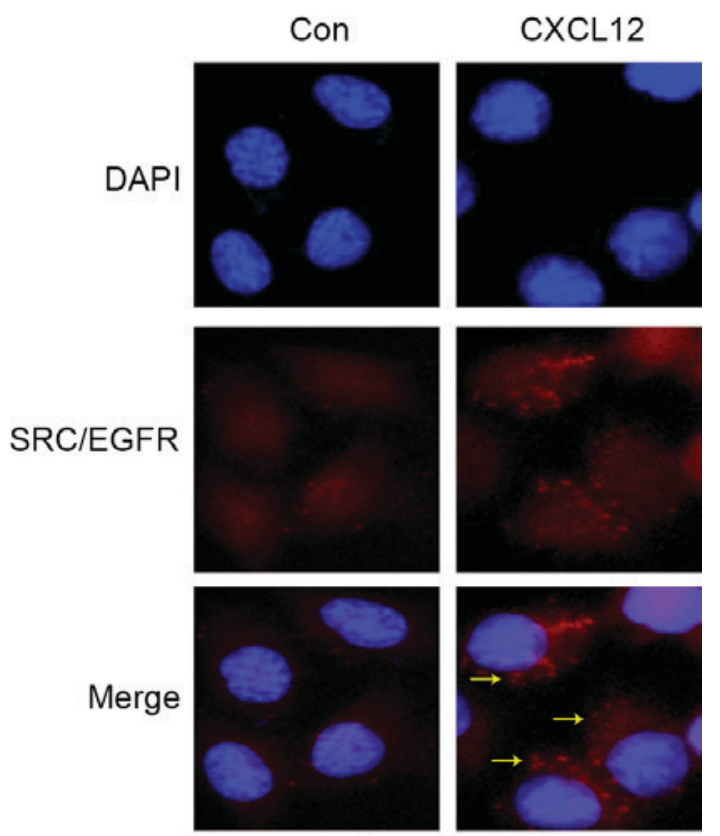

Figure 5. Formation of the SRC/EGFR heterodimer is induced by CXCL12. (A) Serum-starved MGC-803 cells were treated with CXCL12 for 5 min, 30 min or $3 \mathrm{~h}$. Whole cell lysates were immunoprecipitated with anti-SRC antibody. SRC and EGFR levels were analyzed using western blot analysis. Input represents cell lysates that were not subjected to immunoprecipitation or antibodies as an IP control. (B) The SRC/EGFR complex was detected using Duolink in situ proximity ligation assay following stimulation with $100 \mathrm{ng} / \mathrm{ml} \mathrm{CXCL12} \mathrm{for} 3 \mathrm{~h}$ in MGC-803 cells. Red fluorescence, interaction of SRC with EGFR; blue, nucleus; yellow arrows, foci of interaction between SRC and EGFR on the merged image (magnification, x60). (C) Serum-starved MGC-803 cells were pretreated with $10 \mu \mathrm{M}$ SRC inhibitor PP 2 for $2 \mathrm{~h}$ and then treated with $100 \mathrm{ng} / \mathrm{ml} \mathrm{CXCL12} \mathrm{for} 3 \mathrm{~h}$. The interaction between SRC and EGFR was detected using immunoprecipitation. CXCL12, stromal cell-derived factor $1 \alpha$, SDF-1 $\alpha$; PP2, SRC inhibitor; EGFR, epidermal growth factor receptor; IP, immunoprecipitation; Con, control.

Aberrant activation or overexpression of EGFR contributes to tumor progression (28). CXCR4 is a seven-transmembrane trimeric GPCR, which is a type of receptor that may transactivate EGFR via ligand-dependent and ligand-independent mechanisms (29). Firstly, CXCL12/CXCR4 stimulates ectodomain shedding of EGFR ligands mediated by ADAM, including amphiregulin, EGF, epiregulin and HB-EGF, and mediates the activation of EGFR (10). A previous study established that HB-EGF and CXCL12 together enhance the amphiregulin shedding from NUGC4 cells, serving an important role in peritoneal carcinomatosis from gastric cancer (11). Secondly, SRC promotes the formation of the Shc/Grb2/SoS complex and activation of the intracellular tyrosine kinase domain of EGFR (18). In breast and ovarian cancer cells, the interaction of CXCL12 to CXCR4 activates EGFR in a SRC kinase-dependent mechanism $(10,30)$. In the present study, following exposure to CXCL12, there was a gradual increase in the phosphorylation of SRC, alongside the activation of EGFR. PP2 inhibition of SRC suppressed the migration ability and activation of EGFR. In addition, treatment with C225 or the knockdown of the EGFR gene inhibited CXCL12-induced ERK/Akt phosphorylation, indicating that these two signaling pathways are regulated by CXCL12/CXCR4-induced EGFR transactivation. Therefore, these results suggested that inclusive of the first hypothesis, there may be a potential
SRC-dependent mechanism of EGFR intracellular activation in CXCL12/CXCR4-induced gastric cancer cell migration.

To elucidate the underlying regulatory mechanisms of SRC involved in EGFR activation in CXCL12/CXCR4-induced gastric cancer cell migration, the interaction between SRC and EGFR was investigated. SRC interacts with multiple receptor tyrosine kinases via its $\mathrm{SH} 2$ domain and promotes the activation of multiple signaling pathways $(19,31,32)$. EGFR and SRC form a stable complex when exposed to irradiation in lung cancer cells (33). Our previous study reported the formation of the Met/SRC/EGFR complex was induced by cetuximab in colon cancer cells as a resistance mechanism, and the interaction of SRC/EGFR heterodimers antagonize apoptosis induced by tumor necrosis factor-related apoptosis-inducing ligand in gastric cancer cells $(23,34)$. However, the function of the interaction of the SRC and EGFR heterodimer in the regulation of CXCL12-induced EGFR activation remains to be elucidated. Co-immunoprecipitation results demonstrated that CXCL12 induced the formation of SRC/EGFR heterodimers. In addition, SRC inhibitors reduced the formation of the SRC/EGFR complex stimulated by CXCL12. To the best of our knowledge, the present study is the first to identify that CXCL12 induces EGFR activation, at least partially, via the SRC-EGFR heterodimer complex. 
AMD3100 is a highly specific chemokine receptor CXCR4 antagonist, which is also termed plerixafor or Mozobil ${ }^{\circledR}$. In 2008, AMD3100 was approved by the Food and Drug Administration for patients with non-Hodgkin's lymphoma or multiple myeloma (25). Numerous clinical trials using the anti-CXCR4 antibody have been initiated in preclinical, phase I or phase II trials for solid tumor treatment with encouraging results (35). In addition, SRC kinase inhibitors, including saracatinib, dasatinib and bosutinib, are administered to patients with solid tumors (36). Montero et al (37) supported the use of dasatinib in combination with a number of treatments for solid tumors. Plerixafor combined with SRC inhibitors and chemotherapy or radiotherapy may aid individualized patient management, particularly in patients with metastatic gastric cancer that have high expression levels of CXCR4 or CXCL12. However, further experimental and clinical studies are required to confirm the results of the present study.

In conclusion, the present study indicated that SRC mediates EGFR activation through the formation of SRC/EGFR heterodimers, and that activated EGFR stimulates ERK/Akt pathways in CXCL12/CXCR4-induced gastric cancer cell migration. These results provide novel insight into the molecular network of the CXCL12/CXCR4 pathway in gastric cancer cell migration.

\section{Acknowledgements}

The present study was supported by the Chinese National Foundation of National Sciences (grant nos. 81572374, 81201615,81401938 and 81372547) and the Natural Science Foundation of Liaoning Province (grant nos. 2014021069, 2014021089 and LZ2015073).

\section{References}

1. Torre LA, Bray F, Siegel RL, Ferlay J, Lortet-Tieulent J and Jemal A: Global cancer statistics, 2012. CA Cancer J Clin 65: 87-108, 2015.

2. Shah MA: Update on metastatic gastric and esophageal cancers. J Clin Oncol 33: 1760-1769, 2015.

3. Van Cutsem E, Sagaert X, Topal B, Haustermans K and Prenen H: Gastric cancer. Lancet 388: 2654-2664, 2016.

4. Zou YR, Kottmann AH, Kuroda M, Taniuchi I and Littman DR Function of the chemokine receptor CXCR4 in haematopoiesis and in cerebellar development. Nature 393: 595-599, 1998.

5. Cojoc M, Peitzsch C, Trautmann F, Polishchuk L, Telegeev GD and Dubrovska A: Emerging targets in cancer management: Role of the CXCL12/CXCR4 axis. Onco Targets Ther 6: 1347-1361, 2013.

6. Ying J, Xu Q, Zhang G, Liu B and Zhu L: The expression of CXCL12 and CXCR4 in gastric cancer and their correlation to lymph node metastasis. Med Oncol 29: 1716-1722, 2012.

7. Wang X, Zhang H, He H, Shen Z, Tang Z, Xu J and Sun Y: Prognostic value of stromal cell-derived factor 1 expression in patients with gastric cancer after surgical resection. Cancer Sci 105: 1447-1456, 2014.

8. Ohtsu H, Dempsey PJ and Eguchi S: ADAMs as mediators of EGF receptor transactivation by $\mathrm{G}$ protein-coupled receptors. Am J Physiol Cell Physiol 291: C1-10, 2006.

9. Hart S, Fischer OM, Prenzel N, Zwick-Wallasch E, Schneider M, Hennighausen L and Ullrich A: GPCR-induced migration of breast carcinoma cells depends on both EGFR signal transactivation and EGFR-independent pathways. Biol Chem 386: 845-855, 2005.

10. Kasina S, Scherle PA, Hall CL and Macoska JA: ADAM-mediated amphiregulin shedding and EGFR transactivation. Cell Prolif 42: 799-812, 2009
11. Yasumoto K, Yamada T, Kawashima A, Wang W, Li Q, Donev IS, Tacheuchi S, Mouri H, Yamashita K, Ohtsubo K and Yano S: The EGFR ligands amphiregulin and heparin-binding egf-like growth factor promote peritoneal carcinomatosis in CXCR4-expressing gastric cancer. Clin Cancer Res 17: 3619-3630, 2011.

12. Natarajan K and Berk BC: Crosstalk coregulation mechanisms of $\mathrm{G}$ protein-coupled receptors and receptor tyrosine kinases. Methods Mol Biol 332: 51-77, 2006.

13. Hopkins MM, Liu Z and Meier KE: Positive and negative cross-talk between lysophosphatidic acid receptor 1 , free fatty acid receptor 4, and epidermal growth factor receptor in human prostate cancer cells. J Pharmacol Exp Ther 359: 124-133, 2016.

14. Fischer OM, Giordano S, Comoglio PM and Ullrich A: Reactive oxygen species mediate Met receptor transactivation by $\mathrm{G}$ protein-coupled receptors and the epidermal growth factor receptor in human carcinoma cells. J Biol Chem 279: 28970-28978, 2004.

15. Chinni SR, Yamamoto H, Dong Z, Sabbota A, Bonfil RD and Cher ML: CXCL12/CXCR4 transactivates HER2 in lipid rafts of prostate cancer cells and promotes growth of metastatic deposits in bone. Mol Cancer Res 3: 446-457, 2008.

16. Martin GS: The hunting of the Src. Nat Rev Mol Cell Biol 2: 467-475, 2001

17. Bendinelli P, Maroni P, Matteucci E and Desiderio MA: Comparative role of acetylation along c-SRC/ETS1 signaling pathway in bone metastatic and invasive mammary cell phenotypes. Biochim Biophys Acta 1813: 1767-1776, 2011.

18. Luttrell LM, Ferguson SS, Daaka Y, Miller WE, Maudsley S, Della Rocca GJ, Lin F, Kawakatsu H, Owada K, Luttrell DK, et al: Beta-arrestin-dependent formation of beta 2 adrenergic receptor-Src protein kinase complexes. Science 283: 655-661, 1999.

19. Zhang S, Huang WC, Li P, Guo H, Poh SB, Brady SW, Xiong Y, Tseng LM, Li SH, Ding Z, et al: Combating trastuzumab resistance by targeting SRC, a common node downstream of multiple resistance pathways. Nat Med 17: 461-469, 2011.

20. Stabile LP, He G, Lui VW, Thomas S, Henry C, Gubish CT, Joyce S, Quesnelle KM, Siegfried JM and Grandis JR: c-Src activation mediates erlotinib resistance in head and neck cancer by stimulating c-Met. Clin Cancer Res 19: 380-392, 2013.

21. Peiró G, Ortiz-Martínez F, Gallardo A, Pérez-Balaguer A, Sánchez-Payá J, Ponce JJ, Tibau A, López-Vilaro L, Escuin D, Adrover E, et al: SRC, a potential target for overcoming trastuzumab resistance in HER2-positive breast carcinoma. Br J Cancer 111: 689-695, 2014.

22. Boerner JL: Role of SRC family kinases in acquired resistance to EGFR therapies in cancer. Cancer Biol Ther 8: 704-706, 2009.

23. Xu L, Qu X, Li H, Li C, Liu J, Zheng H and Liu Y: Src/caveolin-1-regulated EGFR activation antagonizes TRAIL-induced apoptosis in gastric cancer cells. Oncol Rep 32: 318-324, 2014.

24. Zhao L, Liu S, Che X, Hou K, Ma Y, Li C, Wen T, Fan Y, Hu X, Liu Y and Qu X: Bufalin inhibits TGF- $\beta$-induced epithelial-to-mesenchymal transition and migration in human lung cancer A549 cells by downregulating TGF- $\beta$ receptors. Int J Mol Med 36: 645-652, 2015.

25. DiPersio JF, Uy GL, Yasothan U and Kirkpatrick P: Plerixafor. Nat Rev Drug Discov 8: 105-106, 2009.

26. Nagasawa T, Hirota S, Tachibana K, Takakura N, Nishikawa S, Kitamura Y, Yoshida N, Kikutani H and Kishimoto T: Defects of B-cell lymphopoiesis and bone-marrow myelopoiesis in mice lacking the CXC chemokine PBSF/SDF-1. Nature 382: 635-638, 1996.

27. Ratajczak MZ,Zuba-Surma E, Kucia M, Reca R, Wojakowski W and Ratajczak J: The pleiotropic effects of the SDF-1-CXCR4 axis in organogenesis, regeneration and tumorigenesis. Leukemia 20: 1915-1924, 2006.

28. Guo G, Gong K, Wohlfeld B, Hatanpaa KJ, Zhao D and Habib AA: Ligand-independent EGFR signaling. Cancer Res 75: 3436-3441, 2015.

29. Bhola NE and Grandis JR: Crosstalk between G-protein-coupled receptors and Epidermal growth factor receptor in cancer. Front Biosci 13: 1857-1865, 2008.

30. Porcile C, Bajetto A, Barbieri F, Barbero S, Bonavia R, Biglieri M, Pirani P, Florio T and Schettini G: Stromal cell-derived factor-1alpha (SDF-1alpha/CXCL12) stimulates ovarian cancer cell growth through the EGF receptor transactivation. Exp Cell Res 308: 241-253, 2005

31. Bromann PA, Korkaya $\mathrm{H}$ and Courtneidge SA: The interplay between Src family kinases and receptor tyrosine kinases. Oncogene 23: 7957-7968, 2004. 
32. Parsons JT and Parsons SJ: Src family protein tyrosine kinases: Cooperating with growth factor and adhesion signaling pathways. Curr Opin Cell Biol 9: 187-192, 1997.

33. Dittmann K, Mayer C, Kehlbach R, Rothmund MC and Peter Rodemann H: Radiation-induced lipid peroxidation activates src kinase and triggers nuclear EGFR transport. Radiother Oncol 92: 379-382, 2009 .

34. Song N, Liu S, Zhang J, Liu J, Xu L, Liu Y and Qu X: Cetuximab-induced MET activation acts as a novel resistance mechanism in colon cancer cells. Int J Mol Sci 15: 5838-5851, 2014.
35. de Nigris F, Schiano C, Infante T and Napoli C: CXCR4 inhibitors: Tumor vasculature and therapeutic challenges. Recent Pat Anticancer Drug Discov 7: 251-264, 2012.

36. Mayer EL and Krop IE: Advances in targeting SRC in the treatment of breast cancer and other solid malignancies. Clin Cancer Res 16: 3526-3532, 2010.

37. Montero JC, Seoane S, Ocaña A and Pandiella A: Inhibition of SRC family kinases and receptor tyrosine kinases by dasatinib: Possible combinations in solid tumors. Clin Cancer Res 17: 5546-5552, 2011 